\title{
STAKEHOLDERS' PERSPECTIVES IN RELATION TO THE VALUE OF EDUCATION IN RURAL CHINA
}

\author{
Qinhan Zhang ${ }^{1 *}$, Bruce Waldrip ${ }^{2}$ and Megan Short ${ }^{3}$ \\ 1,2,3 University of Tasmania
}

\begin{abstract}
This paper investigates the perspectives held by stakeholders in relation to education in rural China, in light of social changes stemming from rapid economic growth. Historically, rural citizens are more likely to experience potential social and economic injustice by the implementation of the household registration (hukou) system and other national polices, especially in relation to the provision of education. These inequalities between rural and urban communities not only influence the quality and opportunities afforded by education, but also shape people's perception of the value of education. This paper reports on research that explored stakeholders' perception of the value of education in rural China and explored the associated reasons for stakeholders holding these opinions from three aspects, including social mobility, gender and culture. The research data include 669 student questionnaires, 456 parent questionnaires and 26 interviews with students, parents and grandparents from a relatively poor county of He Bei province in Northern China. This investigation explores that the way in which social mobility, gender, and traditional cultural values shape stakeholders' perception of the value of education. The findings indicated that grandparents tend to have different perspectives from the parents and students in terms of reasons for their acceptance of the significance of education due to the diversity of understanding upward social mobility. Meanwhile, although the gender of students is not a significant issue, it cannot be ignored that some stakeholders still consider that a boy's education is intrinsically more valuable than a girl's education. This investigation also offers a cultural 'lens' through which to explore some of the reasons for parents' and grandparents', influences on students' own perspectives. The result of this research provides an in-depth understanding of the causes of impacting on stakeholders' perception of the importance of education in rural China.
\end{abstract}

Keywords: Rural education, China, the value of education, stakeholders' perspective

\section{INTRODUCTION}

After the end of the 'Great' Cultural Revolution, the implementation of the 'Reform and Open Up' policy has dramatically boosted development of the Chinese economy since 1978. Following the progress of modernization, the disposable personal income in China has increased from $343 \mathrm{CNY}$ (China Yuan) in 1978 to 28844 CNY in 2014 (The National Bureau of Statistic of China, 2014). However, the irrational mechanism of allocating social resources has established an enormous socio-economic gap between rural and urban regions. At the same period, Chinese people did not equally benefit from the 'miracle' economic achievement. The income gap between rural and urban citizens has been widening and reached to 1:3.1 in 2009. (The National Bureau and statistic of China, 2009). It means that an urban person' income was, on average, 3.1 times that of a rural person. In the social aspect, since 1955, existence of Household registration system (Hukou) has divided Chinese citizens into a rural-urban dichotomy and created the various social barriers to prevent rural people from becoming the urban citizens (Fuligni \& Zhang, 2004). The citizens from two categories are entitled to characteristically different social service provision, including education, health care, old-age pension and employment opportunities, in absolute favour of urban (Non-agricultural) Hukou holder (Wu \&

Corresponding Author: *qinhanz@utas.edu.au 
Donald, 2004). These socio-economic disparities between rural and urban societies has led to inequalities between rural and urban education.

While the Chinese government has increased its investment in rural education in order to achieve the goal of universal free compulsory education (Glazebrook \& Song, 2013), the overall quality of rural schools is still poor in general, due to the lack of both facilities and qualified teachers (Yiu \& Adam, 2013; Zhang, Li \& Xue, 2015). This issue of quality has resulted in substantially reducing the possibility of rural students attending senior colleges and universities as these are beyond compulsory schooling. One of the results of inequality is that the difference of educational opportunities between urban and rural students was 5.8 times nationwide, based on a result of the large-scale study undertaken jointly by the World Bank and the Ministry of Education of People's Republic of China in 1998 (Zhang, 2004).

Considering the restricted educational opportunities in rural China, rural citizens are also subject to various social and economic injustices as a result of the implementation of the household registration (Hukou) system and other national polices, such as school admission policies and College Entrance Examination. Given the scope and depth of the differences between rural and urban education in China, it could be assumed that rural citizens' perception of the value and the importance of education could be shaped by the special socioeconomic reality in modern China (Huang, 2012). The vast majority of Chinese rural citizens could be recognized as the stakeholders of rural education, including parents, grandparents and students, because they have both direct and indirect contacts with schools in rural China. This research focus on the exploration of how this disparity impact on rural stakeholders' perception of the value of the education and rural students' attitudes towards schooling. Therefore, the research question is "What are the perspectives of stakeholders in relation to education in rural China?"

\section{Rural Education in China}

In rural areas, the basic education system is the same as in urban schools. Students normally take 12 years to finish their basic education, which includes 6 years of primary education, 3 years in junior secondary school and 3 years in senior college. Since 1986, the first nine years of schooling became compulsory education, including primary and junior secondary education, because of the implementation of "Compulsory Education Law of PRC" (National People's Congress, 1986). At the end of primary and second junior secondary education, every student is required to take "graduation examination" that is a completion test for the level. To enter college or university, students sit an entrance examination (Bo $\&$ Anne, 2015). In general, graduates of junior middle schools have only one chance of passing exam of entrance senior college. If they fail in the exam, they can choose to go to vocational schools or some private senior colleges to continue their schooling. With the college entrance examination, there are no limitations on the number of the times of taking the examination and applicants' age or educational background.

Notwithstanding the similarity of the structure in basic education between rural region and urban regions, rural education is characterized as facilitating less opportunity for higher education. Even though the Chinese government has increased its investment in rural education in order to achieve the goal of universal free compulsory education, the quality of education in rural areas is still poorer in general terms (Glazebrook \& Song, 2013). The lack of qualified teachers and facilities can be considered as two important causes of the low quality education in rural education and performance of educational inequality. Yiu and Adams (2013) argued that the teachers who are working rural schools often face difficult situations, and their salaries could be paid late. In addition, it was difficult for rural school to recruit qualified teachers. Thus, rural schools employed some teachers who lacked the required teaching qualifications. As the result, rural students were often educated by the least qualified teachers. By comparison, in general, the urban schools had qualified teachers and high-ranking teachers who had at least bachelor degree and teaching certifications (Paine \& Fang, 2007). Moreover, the earlier research (Knight \& Shi 1996) advocated rural schools in China not only significantly less funding but also more decentralized financial support than urban schools. The insufficient funding caused many problems of rural schools, such as the lack of teaching equipment, 
over-size number of students, poor quality of school buildings.

\section{Stakeholders' perspectives on educational value in rural China}

In rural China, the stakeholders of education include students, parents and grandparents. Students have been involved in the learning procedures at school, therefore, they are direct participants of rural education. As guardians and caregivers of students, parents have connected with their children's learning process and are supposed to join the parents-teacher conference at schools. In this sense, they can be regarded as stakeholders of rural education. Additionally, Ye and Murray (2005) argued that grandparents play part of parents' role in migrant workers' family, because they generally look after grandchildren when children's parents are working in urban areas. Thus, grandparents also could be considered as stakeholders of rural education as well.

If students affirm the importance of educational value for their further, it can be the precondition of positive attitude towards learning. As, Triandis (1971) advocated that students understanding the value of education will intrinsically influence their attitude towards learning. Zanna and Rempel (1988) pointed out that attitude consists of cognitive, affective and behavioural components. In term of an attitude towards learning, the cognitive component refers to an awareness and understanding of the students' learning activities or target subjects with an evaluation of their significance; it is the basis of student's attitude towards learning and reflects their awareness of the value of learning.

Based on the expectancy-value theory, how students value education and school subjects can directly impact on students' academic outcome. Scholars who subscribe to expectancy-value theory pointed out that individual's choice, persistence and performance depend on their beliefs about how well they could do on the activity and the extent to how they value the activity (Atkinson, 1957 ; Wigfield, 1994). According to Eccles and his colleagues (1983), achievement value portion of the model can be broken into four components: attainment value or importance, intrinsic value, utility value and cost. Among these components, students' acceptance of educational value mainly connects with attainment value, that is, the importance of doing well on a given task, and utility value, which refer to how a task fit into an individual's future plan. Hence, if students fully comprehend value and importance for their further life plan, they can be motivated to achieve certain personal goal of academic attainment and gain degrees or certifications to initiate professional career.

Additionally, the parents' perspectives about the value of education is another important consideration, Walberg's model of educational productivity specified that family environment was one of supplementary or supportive factors affecting the students' academic outcome (Walberg, 1981). Walberg and his colleagues also argue that home environment incorporates educational levels of parents, parental support and aspiration. (Young, Reynolds \& Walberg, 1993). Moreover, Bloom (1986) demonstrated that factors in home environment, including academic support and parents' aspiration for students' success, were found to be highly connected with students' academic achievement and both of the factors strong correlated with parents' perspective about educational importance for their children.

The grandparents' perception could also impact on students' point of view of the value of education. In term of raising children under circumstance of rural China, grandparents play an important role, because Chinese tend to consider that the accountability of caring children not only belongs to the nuclear family, but also to members of the extended family as well. Ye and Murray (2005) states that, in rural region of PRC, the children often left with grandparents when both their parents have become migrant workers. Unfortunately, there is very little research in relation to the effect of grandparents on children's school experience in rural China. Only one Chinese study has specially focused on under the circumstance of rural area by Zeng and Xie (2014) who found that co-resident grandparents' educational level significantly influences the children's academic attainment. Although this lack of research connected with how grandparents value education and whether their perspective can influence their grandchildren or not, it is reasonable to assume that grandparents' perspective could be significantly influenced by 
communist ideology and traditional Chinese, because they impacted 'Planned Economy' and 'The Cultural Revolution' during Mao’s period.

\section{The cultural and socio-economic factors that impact on stakeholders' perspective}

Although the principles of Confucianism were abandoned during Mao's period, these still are considered as the basic of social ethics in modern China. By analyzing the roles of these principles, it can offer a cultural viewpoint to clarify reasons for parents' and grandparents' influences on student's perspective. One of the principles, that has been particularly emphasized in the traditional Confucian ethics (Zhang et al., 2012), is filial piety that can guide people to perceive the parents' and grandparents' influence on their children's perspectives. The principle of piety filial imply that younger people must be deference to older individuals, mostly within a family. Younger people respecting and obeying elders' opinion without questions is a significant quality seen among Chinese (Resick et al. 2011). Thus, in the aspect of understanding educational value, students will generally accept parents' and grandparents' opinions and instructions about education.

The changes of the socio-economic environment in China could also be a factor as well. During the period of planned economy (Mao era), due to implementation of the rigid household registration system, only a tiny fraction of rural citizen had chance to move up to urban area. Attainment of tertiary education and subsequent job assignments was considered as the one of the most popular motivations for this migration (Kirkby, 1985). As the results of post-Mao reforms, rural citizens returned to the position of autonomous producers and resumed having freedom to work for higher incomes from a non-agricultural job in urban regions (Unger, 1994). The certain level of education can be the precondition for rural people working in the high paying jobs.

Meanwhile, as Lu (2001) observed that private entrepreneurs have become a new capitalist class in rural China. This phenomenon affirmed the existence of another approach that could provide opportunities to meet the rural farmer's requirement of upward mobility, even though this class only consist of $1 \%$ of total rural population. In spite of the fact that many private entrepreneurs are generally not highly educated, they still have a high quality of life and respected social status. It cannot be ignored that this social changes can influence stakeholders' perspective about the educational value.

Gender inequality could be another factor influencing stakeholders' perspectives. Connelly and Zheng (2003) deem that the gender disparities in China are concentrated in the poor rural areas, and among lower income households, where there is the competition between siblings for educational resources, and school fees are a burden on the family. Recent studies found that the severity of gender inequality has been reduced, as Hannum, Kong and Zhang (2009) found that there is little evidence of a gender gap in economic investment in education and rural parents' educational attitude and practices toward boys and girls are more complicated and less uniformly negative for girls than commonly portrayed. The growth farmer's incomes and increase in educational opportunities could be a possible reason for the reduction of this disparity. Nevertheless, the inequality still exists in the rural area; and scholars have not conducted any researches into the connection between this bias and stakeholders' perception on educational value in rural China.

\section{RESEARCH METHOD}

A mixed method has been chosen as the main methodological approach for this study, and both qualitative and quantitative data have been collected. According to Creswell (2014), mixed method involves collecting, analysing both qualitative and quantitative data in a research study. The students' and parents' questionnaires was the main method of quantitative data collection, and include a total of 669 student surveys (339 males and 330 females) and 456 parental surveys. With the qualitative data, a total of 26 interviewees were respectively selected from parents, grandparents, teachers and students of the participants, 10 from each groups of parents and students, six from grandparents' group. All of participants came from three primary schools, which located in Xingtang County, Hei Bei province in northern part of China. The Statistic Package for Social Science (SPSS) has been used as a main tool for analysis and One-way ANOVA with post-hoc 
tests was the method in the process of analysing quantitative data. To analyse the qualitative data, several steps were undertaken, including translating, coding, sorting, comparing and contrasting. Through analysing quantitative, the research results could shed light on stakeholders' perceptions towards education in rural China and explore the factors that shape their understanding about the importance of education.

In the questionnaire, the content has been divided into two parts, the student's section and the parent's section. The main section of the student's part consisted of ten questions. Questionnaires of many previous studies in relation to attitude towards education or learning were based on the threecomponent model. For instance, Seker (2011) used the three-component model as theoretical basis to develop a questionnaire for exploring students' attitude towards school and their perception of the value of education. A five-point Likert scale has been used to determine tendency of student's perceptions. Many prior researches (Holfve-Sabel, 2006; Seker, 2011) have used this scale as format of questionnaires.

Four questions are related to the value of education and the importance for themselves. The acceptance of the value and significance of education is the precondition and basis of their perspectives about educational value. Meanwhile, four questions have been incorporated to capture the role of the affective component. These questions concern how often they enjoy learning under the at school and home, in other words, students' perception about their involvement in schools. The last three questions are connected with the students learning habits, such as; the how often focusing on learning, the situation of completing homework and reading or studying custom. Some areas of this questionnaire were partly consistent with modified Mitchell's attitude towards education scale (Ola \& Morahinyo, 2008). Participates' responses in questionnaires were quantified to be digital data for analyzing data.

The second part of the questionnaire is six questions for the participant's parents. The main proposes of asking these questions are to explore parents' understanding about the value of schooling and their expectation of their children's educational level, as some scholars (Bronstein et.al, 2005; Wingfield,
1993) advocated that students learning can be impacted by these factors. Meanwhile, the design of interview questions would also concern results of student and parent survey, because aim of next step is to explore why stakeholders has these perception and opinions.

The semi-structured interview used as the main instrument for the interview part of this research, in order to explore stakeholders' perspectives about school and learning. In this study, three groups of participants were invited to join interview section, including students, parents and grandparents. Based on the results of questionnaires, several questions were asked to explore the reasons that could influence stakeholders' opinions. Parental and grandparental interviews started with five questions which had been prepared in advance for exploring details about encouraging and supervised their students' learning and their aspirations for children's educational level. In addition, content of these questions concerned the difficult in process of caring and supervising children's learning, which could negatively influence the students' academic performance. Then, there were several questions in relation to how they value education and why they hold these opinions. In the students' interviews, participants were required to answer several questions regarding to their attitudes towards school learning and educational value, situation of parental or grandparental involvement in their study and their opinions about effectiveness of these caregivers' involvement.

There is a considerable overlap between questionnaire and interview questions. The findings from questionnaires could provide a picture regarding to the brief opinions of stakeholders in the aspects of perception of the importance of education. In the interview section, questions relate to these issues for examining reasons of the formation of these stakeholders' inclinations. Thus, quantitative data combining with qualitative data could supply adequate evidence for asking the research questions.

\section{Data Analysis}

\section{- Quantitative data}

- The quantitative data was collected before starting the interview section, because the interview questions 
were designed by considering stakeholders' inclinations showed in the results of surveys. The results of the quantitative analysis demonstrate that the vast majority of students respect the value of education and believe that their future will be influenced by their academic achievement.

Table 1: Students' Perception of Importance of Education

\begin{tabular}{llll}
\hline $\begin{array}{l}\text { Statement } \\
\text { number }\end{array}$ & Statement & Mean & Std.Deviation \\
\hline Q5 & Education is extremely important for my future & 1.47 & 0.69 \\
\hline Q6 & $\begin{array}{l}\text { Although the study is important, it does not matter } \\
\text { whether I am studying hard or not. }\end{array}$ & 3.96 & 1.31 \\
\hline Q7 & my future depends on the results of my studying & 2.41 \\
\hline & $\begin{array}{l}\text { When my parents or grandparents talk about the } \\
\text { Qmportance of studying and encourage me to be a } \\
\text { good student, I consider they are right. }\end{array}$ & 1.62 & 0.83 \\
\hline
\end{tabular}

Table 2: Parents' Perspectives on The Importance of Education

\begin{tabular}{llll}
\hline $\begin{array}{l}\text { Statement } \\
\text { number }\end{array}$ & Statement & Mean & Std.Deviation \\
\hline Q4 & $\begin{array}{l}\text { I believe the children's future depends on their } \\
\text { result in school. }\end{array}$ & 0.97 \\
\hline
\end{tabular}

The displayed data of the items five, six and seven in the student' survey (Table 1) indicate that the most of student participants approved the decisive role of education for themselves' current life and future life. The item five (Mean $=1.47$, S.D. $=0.69$ ) is related to how students value education for their future. The data shown in item five of Table one indicate that an overwhelming majority of students, more than $93 \%$,

believed that education is critical for their future, including $61.9 \%$ of students chose to 'strongly agree' and $31.2 \%$ of students selected 'agree'. The quantitative data illustrate that the students from three rural schools widely accepted the opinion of their future significantly influenced by schooling.

The data displayed item six in Table one indicates that the vast majority of students tend to consider that they should make an effort to achieve academically at school. The answers of items six (Mean =3.96, S.D.
$=1.31$ ) present participants' attitude towards consequence of studying hard for themselves. The statistical results demonstrate that $74.8 \%$ of respondents considered that studying hard "matters" for them, whereas, $19.7 \%$ of students believed that it is not important for them to study hard or not, which means that one in five student participants do not accept that they need to put in effort to learn knowledge in school as necessity.

The students' opinions about whether or not the academic performance determining their future can be illustrated by analyzing the quantitative data shown in item seven. The result of this item (Mean. $=2.41$, S.D. $=1.31$ ) is slightly difference from the item five. Although more than half student participants, $63.8 \%$, still agreed that their future is decided by their academic achievement, $28.6 \%$ of respondents disagreeing with the statement, which is much higher by comparison with the answers of item five in which 
only $1.3 \%$ of participants chose the same options. The number of students who chose neutral option increase to $7 \%$ comparing to $5.5 \%$ in item five and $5.4 \%$ in item six. This results indicate that a majority of students still agreed that their future depends on their academic achievement, whereas, there are certain number of students who hold contrary opinions, even though they, almost all, confirmed the significance of education.

The data displayed item 11 in table one shown that most of student respondents tend to accept the parents' and grandparents' opinions regarding to the importance of education and their encouragement to students achieving academically. The result of item 11 (Mean. $=1.62$, S.D. $=0.83$ ) indicated that $84.5 \%$ of student participants chose options, 'almost always' and 'usually'. It means, in the most cases, they agree with their parents' and grandparents' ideas about the value of education and accept their encouragement. In contrast, there are only $2.5 \%$ of students who chose option, "seldom" or "almost never". The result indicates that only very few rural students did not accept parent's and grandparent's viewpoints of the value of education and their inspiration for students' academic achievement.

The data shown in Table 2 indicate that the majority of parents, $54.3 \%$, agreed with the statement about the decisive function of educational outcome in their children's future, although some parents tended to have a neutral perspective in the statement. In the guardian questionnaire, the guardians were required to state their opinions about whether or not the academic result determining children's future in item four, which is same statement with item seven of student's version of the questionnaire. The answers are different between students and their parents/grandparents. Although more than half respondents agreed this statement in the both groups, the option "strongly agree" has only been chosen by $16.4 \%$ of guardian participants. By comparison, the percentage is approximately double in the data of student questionnaire, $31 \%$. Furthermore, there are $21.9 \%$ of guardian participants chose the option 'neutral', which is three times than percentage in students' statistic. Interestingly, the mean of parents' answers, 2.22, is lower than the students', 2.41, indicating that the percentage of parents disagreed this statement is less than the student participants'.
By comparing the two sets of data, means that, on the whole, guardians retain a more negative attitude towards the decisive effect of academic performance than the students, but nevertheless they also tend to have relatively neutral point of view.

- Qualitative Data

1. Parents and Grandparents

In the process of conducting the qualitative data, the interviewees were required to answer several questions related to their perspectives of the importance of education. In the interviews with parents, eight of 10 parents accepted that education was significant factor for their children and could be important determining their children's future.

Father $\mathrm{Li}$ who is an internal migrates worker mentioned that:

"People without education cannot do
anything, when I was working outside
I seen that. After working outside, I
realized that education was very
important. However, in the past, I
considered whether people attending
school or not were same. I had been
working outside for several years
before my child was born, so I always
hope that my child can get higher
academic achievement."

Father Zhang said that:

"Human beings should study; a person without education even cannot survive in the society and is wasting life."

All grandparent interviewees accepted the significance of education in the same way as well. Liu, who is caring for his two grandchildren, said that:

"In the future, people cannot live
without education. A person without
knowledge from schools even cannot
do farming work. Children should
study at school and have to work hard
for learning knowledge."

However, two parents held a different opinion from other eight parents who believed education was the decisive choice for children's future. The father Huang argued that: 
"I disagree with the viewpoint about the inevitability of children's academic achievement determining their future. The high educational qualification is not equal to high ability of doing other things. In my village, a person graduated from university and received Bachelor degree, but he has always been working for a boss who did not attend university."

Another mother, $\mathrm{Hu}$, held the same opinion, although she considered that the academic achievement could influence her daughter's future.

"Many people become bosses of factories, but without much schooling. In my village, a person who only finished primary schooling has iron powder factory and several companies. He can make a lot of money."

The parents believed that the scholarship seen as the path of social mobility. Nine out of ten parents had high aspiration for children's schooling, because the high academic qualification could be considered as an essential prerequisite for finding a decent job from their perspective, then, children can jump out of the peasant class and leave the mountainous area.

\section{Mother Hu said:}

"I hope my child hard working in the school, so he can go outside and do not need to live in this mountainous area anymore. I do not wish him as us doing farm work and suffering life."

Mother Liu pointed out that:

\footnotetext{
"In the countryside, we see that people without education will not have the future. Many young people who attended vocational schools and got diploma, then, they could not find a decent job. Hence, I hope my children can go to university and receive the highest degree."
}

The rural parents and grandparents indicate that the reasons for their acceptance of educational significance is not only because this is critical for their children's future, but also because education provides the possibility for their children contributing to the development of the country. Especially, the grandparents tend to emphasize the link between children's academic achievement and the national progress. Furthermore, the grandparents shared their opinion with their grandchildren when they were encouraging their children to be good students.

Grandfather Xia said:

"The education can not only change your destiny, but also let you can contribute to the country by using you own strength. Do good and important things for our country."

Grandfather Li mentioned that:

"I would like see my granddaughter
receiving higher education and
getting outstanding academic result,
than she can be useful person for
country. I do not want to see her
doing business in the future, because
it is useless for the country."

Grandfather Xing expressed that:

$$
\begin{gathered}
\text { "People without education cannot do } \\
\text { anything today, so I hope my } \\
\text { grandson can become a man of } \\
\text { tremendous promise for the state, at } \\
\text { least, having Bachelor degree in the } \\
\text { future." }
\end{gathered}
$$

It is interesting that grandfather Liang who are taking care of two girls do not wish his granddaughter to receive excessively high degree, because he considers it cannot benefit a girl. The grandfather commented:

$$
\begin{gathered}
\text { "I do not have high demand, as long } \\
\text { as they can attend university, than } \\
\text { can find a job. I am satisfied with } \\
\text { that. They are girls, if they received a } \\
\text { very high level of academic } \\
\text { qualification; it could negatively in } \\
\text { influence their future, marriage, for } \\
\text { example." }
\end{gathered}
$$

\section{Students}

In the student interviews, the nine of ten interviewees mentioned that their parents and grandparents had told them about possible benefit for their future, if they study hard and have outstanding academic performance in the school. All of them agree with their parents' and grandparents' ideas about the significance of education and academic performance.

Student Li students expressed that: 
"My parents and grandparents told me to study hard; then, I can attend university and make money for having better life in the future."

Student Wang said:

"They (parents and grandparents)
told me that if I make effort in
studying, and then, I can go to a good
university, I will have a decent job
and become a man of promise."

Surprisingly, a female student, Xing commented that her parents and grandparent never told her the significance of schooling, they even never encouraged her to make an effort in school learning. In contrast, her parents and grandmother often talk to her older brother about the importance of education and encourage him. Xing said:

"My parents and grandmother never
told me how important education is; I
think this is not right. I received poor
results in school, because they never
told me the importance of education.
However, I consider if I gain the high
academic achievement, I can easily
find job, therefore the education is
very important for me. They only like
my old brother and encourage him to
study hard, maybe because he is
outstanding students in school. They
do not like me, my results are poor, I
do not know."

Furthermore, five of 10 student interviewees harbor the desire of returning and rewarding their parents as a main factor of motivating them to make effort in school learning, except for adopting parents' opinions. A top student, Li, of school said:

"My father is hard working in the city
(for saving money for supporting Li's
schooling in the future, she mentioned
in the middle of this interview), even
though, the Chinese new year
approached, he was still working. In
my heart, I made a decision that I
must working hard in school for my
father having good life in the future.
Therefore, I want to return and
reward my father."

On the contrary, one student example from a parent' description consider the education being less value for her future. Mother Liu mentioned that her daughter tends to have negative attitude towards schooling and remain different point of view from her mother in term of understanding the significance of education, Liu said:

"I told she that the people with high academic qualification are quite cultivated and easy to find a job. If a person only attends an average school, then, cannot find a good job and jump out from farmer class. My daughter is not convinced. Once, she said that whether I learn or not in the school is not important. I can learn some skills."

\section{DISCUSSION}

The research question is 'how do stakeholders perceive education in rural China?' From the analysis of quantitative and qualitative data, the importance of education is acknowledged by the overwhelming majority of stakeholders.

\section{- $\quad$ Social Mobility}

All of the parental and grandparental interviewees have the aspirations for their children attending universities and receiving undergraduate or postgraduate degrees. The student interviewees also tend to accept the opinions of their parents and grandparents as well. However, around $45 \%$ of respondents of the parental questionnaire do not believe that the children's future depends on their results in schools. This opinion is also reflected in the parental interviews in which two participants disagree with the viewpoint about the inevitability of children's academic achievement determining their future. According to $\mathrm{Wu}$ and Donald (2004), the existence of household registration (hukou) system has resulted in the fact that converting one's rural hukou to an urban status has become a fundamental aspect of upwards social mobility in rural China since 1955. Thus, the vast majority of parent and grandparent interviewees have made clear that they want to their children to live in urban areas and to move away from their hometown. The student interviewees also agreed with the parent's and grandparents' ideas regarding their future.

On the other hand, a certain percentage of the interview and questionnaire's participants disagree that education is a key factor of upward social mobility under the circumstance of rural China. Two 
parent interviewees believed that people with degrees from universities might not be successful as some people without much education. The questionnaire data also illustrates that the opinion, 'my future depends on the results of my studying', is disagreed by nearly $30 \%$ of the student respondents. This phenomenon could be caused by the reduced effectivity of education as a social mobility ladder since 1990s. The increasing difficulty for new university graduates to secure jobs has been regarded as one of most serious social problems in present China (Feng, 2009). Intensifying competition in the employment market and the impact of 'guanxi', which refer to a person's network of relationship, brings more severe hardship to new university graduates with a rural origin (Wu \& Zheng, 2008). Even though rural graduates find a job in a formal position in commercial organizations or governmental agencies, sky-rocking housing prices and living costs in Chinese urban areas make it difficult for them to repay what their parents have invested in their education as well (Huang, 2012). Thus, stakeholders' perception of the value of education could be negatively influenced by the reduced effectiveness of education as social mobility ladder.

The grandparent interviewees tend to have different perspectives from the parent and student participants in terms of reasons for their acceptance of the significance of education, which also correlates with how they understand the educational function of upward social mobility. The grandparent interviewees emphasized the link between children's education and national progress. It is implied that grandparents wish their children to establish some connections with "the country". In Chinese cultural and social context, it means having positions in the government, which is controlled by the Chinese Communist Party (CCP), and other organizations or companies which having national backgrounds. The causes of this perspective could be the impact of life experience during Mao's era. Scholars deemed that a peasant could achieve social mobility in three ways in this period. Firstly, higher education: the government assign formal positions in organizations of CCP, governmental agencies or state-owned enterprises to rural young graduates who automatically receive non-agricultural hukou (Wu \& Donald, 2007). Secondly, the career path of becoming a cadre and attending membership of CCP allowed one to be a member of the state's administrative system (Anita et al., 1984). Finally, a rural youth can join the people's Liberation Army (PLA), thereby becoming a member of CCP and the getting promoted in the army or being discharged from military service into local government or stateowned enterprises (Sulamith \& Jack, 1990). Aforementioned three ways was the main paths of upward social mobility in rural China during Mao's era and connected with public service and CCP. The grandparents' generation was growing up within this social atmosphere, therefore, their ideas are still impacted by some social ideology of Mao's era. In the aspect of understanding the value of education, the grandparent interviewees attend to underline the relationship between children's education and national progress. Because, contributing to national progress was the only way for people to promote their own social status when grandparents were young.

\section{- $\quad$ Gender}

Based on the results of qualitative and quantitative analysis, the gender factor of students is not a significant issue in the aspect of affecting parent and grandparent participants' perception of the importance of education and educational aspirations for their children or grandchildren. In the questionnaire, the parent respondents were required to choose options in relation to their children's gender and expectations for their children's level of education. The data indicated that there was not a major overlap between two issues. In the interview section, all of parents and grandparents did not give preference to neither boy's nor girl's education. This results are in accordance with findings of previous studies regarding to gender equality in education in rural China. Huang (2012) argue that gender equality of rural education in China has greatly improved, whether during the compulsory period (from year one to year nine) or university preparatory period (from year 10 to year 12). It is rational to assume that Stakeholders' perception can be shaped by the present situation of labor market in rural China. If a rural boy fails to attend universities, they can learn some manual skills through vocational schools or apprenticeship. They still can have a decent income in rural areas, based on manual skills these are considered unsuitable for girls (Huang, 2012). Girls without academic achievement can do non-farming 
jobs in the countryside or other urban areas, after getting married, taking care the family will be the main task for rural girls who also have to face a tightly constrained job market for married females in rural areas (Ross, 2011). Thus, following academic path can be regarded as the only way for rural girls to have better lives and upward social status. This social reality in rural China promote the improvement of gender equality of rural education and shape stakeholders' attitudes towards girls' education in rural China.

However, it cannot be ignored that a small number of stakeholders still give preference to boy's education. In student interviews, one girl reported that her parents and grandparents always encourage her older brother to achieve academically in the school, whereas, they never stimulate this girl to become an outstanding student. This girl assumed this could be because she had poor academic records in the school, compared to her older brother. The girl did not show the academic promise, so the parents and grandparents did not expect higher return from her in the future. The finding of research from Connelly, Roberts and Zheng (2010) could provide an insight into this girl's case. They point out that Chinese rural parents have a strong incentive behind the investment in academically stronger children, because of the higher return from these children. On the other hand, Hannum, Kong \& Zhang (2009) suggest, regarding to rural female students, showing early academic promise attend to be particularly important. This means girls normally gain priority over their brothers when their academic results are significantly better and when their promise of success is absolute. Thus, this girl's experience imply that a small number of shareholders could still have opinions of indirect gender bias when they value the importance of education.

\section{- Culture}

The data of interviews and questionnaire indicated that the overwhelming majority of interviewees tends to accept their parents' and their grandparents' opinions regarding to the value and the importance of education. This students' inclination could be shaped by Confucian principle of filial piety that refers to love, respect and care for parents and ancestors (Luo $\&$ Zhao, 2012). It has been particularly emphasized in
Chinese traditional ethics (Zhang et al., 2012). One of the principles of filial piety implies that younger people must deference to older individuals, mostly within a family. Younger people's respect of their obeying elders' opinion without questions is a significant quality seen among Chinese (Resick et al. 2011).

Moreover, the half of student interviewees harbor the desire of returning and rewarding their parents as one of the main factors of influencing their perception of the value of education and motivating them to make effort in school learning. The desire of returning and rewarding their parents can be considered as another principle of filial piety. The practice of filial piety is expected to sustain intergenerational so that sufficient financial, physical, and emotional support to elderly parents from offspring (Johnson, 1983). Meanwhile, Ho (1994) argue that rural elders tend to have higher expectations of filial piety than their urban counterparts. Because of the lack of comprehensive social welfare programs for old adults in rural China, rural grandparents and parents have to dependent on support from their offspring when they lose their ability to work (Luo \& Zhan, 2012). Therefore, many student interviewees have been taught and have accepted the idea of filial piety, since childhood. Duo to the strong connection between upward social mobility and academic achievement in rural China, the most stakeholders believe that only if rural young people receive a degree from a university and have a decent job, then he or she can provide sufficient financial support for elderly parents. As a result, rural students' desire of returning and rewarding their parents become one of the main factors in the process of them valuing the importance of education.

\section{CONCLUSION}

This current research has conducted an investigation to explore the rural stakeholders' perception of the value of education, to identify enablers and challenges of rural education in China. With the issue of stakeholders' perception, the finding revealed that the overwhelming majority of stakeholder acknowledged education having the decisive influence on children's future. The purpose of this study was also to determine which factors shaped rural people's understanding about the value of education under circumstance of contemporary 
China. By analyzing the qualitative and quantitative data, it has been identified that social mobility, gender and culture are significant influencing factors in this issue.

Duo to social-economic inequity between rural and urban areas and the existence of householder registration system, upward social mobility the decisive factor that impact on the stakeholders' perception of the value of education. The research findings represent a unique contribution in relation to an understanding of grandparents' perception of the importance of education, which tend to be different from other stakeholders.

Furthermore, although the obvious gender bias has not been discovered in quantitative and qualitative data, one student interviewee still pointed out evidence for proving the existence of viewpoints of gender inequality among very few stakeholders. Meanwhile, in order to comprehensively realize stakeholders' perception, the impact of Chinese traditional culture, Confucianism, should be taken into the consideration, especially in the term of explaining students' obedience to parents' and grandparents' opinions regarding to the importance of education.

This study result has provided a brief understanding regarding to rural stakeholders' perception of the value of education and challenges and enablers in rural China. It could be helpful when relative policy makers amend educational policies for improving the quality of rural education to meet stakeholders' demands. It is also significant that policy makers deeply concern on the rationality and necessity of existence of the household registration (Hukou) system, because it has limited the basic right of enjoying education equally among rural citizens of PRC. Moreover, with new rural teachers, especially from the urban areas, it is necessary for them to realize the stakeholders' perception in order to establishing the effective communication with stakeholders and reducing their possibly potential bias towards rural education and rural students.

\section{REFERENCE}

Atkinson, J. W., 1957, Motivational determinants of risk taking behavior. Psychological Review, 64, 359372 .
Bo, H., \& Anne, W. ,2015, Exam-oriented education and implementation of education policy for migrant children in urban China. Education Studies, 41(3), 249-267.

Bloom, B. (1986). The family environment and school learning. One of 46 papers commissioned by the Study Group on the National Assessment of Student Achievement and cited in Appendix B to their final report "The Nation's Report Card" (TM 870 049).

Connelly, R., Robertd, K. \& Zheng, Z.,2010, The impact of circular migration on the position of married women in rural China. Feminist Economics. 16 (1), 3-41.

Creswell, J. (2014). Research design: qualitative, quantitative, and mixed methods approaches (4th ed.) (Thousand Oaks, CA: Sage).

Eccles J. S., Adler, T. F., Futterman, R., Goff, S. B., Kaczala, C. M., Meece, J. L., \& Midgley, C.,1983, Expectancies, values, and academic behaviors. In Achievement and achievement motivation, edited by J. T. Spence. (San Francisco, CA: W. H. Freeman), pp. 75-146.

Feng, Y. ,2009, Looking for springtime: Employment of university graduates. Liberation Daily, February 27.

Fuligni, A. J., \& Zhang, W., 2004, Attitude toward family obligation among adolescents in contemporary urban and rural China. Society for Research in Child Development, 75(1), 180-192.

Glazebrook, K., \& Song, L., 2014, Is china up to the test? A review of theories and priorities for education investment for modern China. China \& World Economy, 21(4), 56-78.

Hannum, E. C., Kong, P. A., \& Zhang, Y., 2009, Family sources of educational gender inequality in rural China: A critical assessment. International Journal of Educational Development, 29(5), 474-486.

Hol-Sabel, M., 2006, A comparison of student attitudes towards school, teachers and peers in Swedish comprehensive schools now and 35 years ago. Educational Research. 48 (1), 55-75.

Huang, Y., 2012, "Jumping Out of the Agricultural Gate" (tiao chu nong men): Social Mobility and Gendered Intra-household Resource Distribution among Children in a Central Chinese Village, 19502012. China Perspectives. 4, 25-33.

Kirkby, R., 1985, Urbanization in China. (New York: Columbia University Press).

Knight, J., \& Shi, L., 1996, Educational attainment and the rural divide in China. Oxford Bulletin of Economics and Statistics, 58 (1), 83-117.

Liu, J., 2011, Expansion and equality in access to Chinese higher education: A cultural perspective. 
(Doctoral dissertation, University of Toronto, 2011). Retrieved from ProQuest Digital Dissertations.

National Bureau of Statistics of China, 2009, China Statistical Yearbook. Beijing: Government of People's Republic of China.

National People's Congress., 1986, Compulsory Education Law of People's Republic of China. Beijing: Ministry of Education.

Ola, B., \& Morakinyo, O., 2008, Metal healthy and attitude towards education of secondary school students in Nigeria. Ife Psychologia. 16 (2), 194-204.

Paine, L., \& Fang, Y., 2007, Supporting China's teachers: challenges in reforming professional development. In Education and Reform in China, edited by E, Hannum. \& J, Park. (New York: Routledge).

Resick. C., Martin, G., Keating, M., Dickon. M., \& Kwan, H., 2011, What ethical leading means to me: Asian, American and European perspective. Journal of Business Ethics, 101, 435-457.

Ross, Heidi.,2011, Challenging the gendered dimensions of schooling: The state, NGOs and transnational alliances. In Women, gender and rural development in China, edited J. Tamara \& S. Sally (Cheltenham, UK: Edward Elgar Publishing), pp.143170.

Seker, H., 2011, Developing a questionnaire on attitude towards school. Learning Environment Research, 14(3), 241-261.

Unger, J.,1994, 'Rich man, poor man': the making of new classes in the Chinese countryside. In In China's quiet revolution, edited by D. Goodman., \& B. Hooper. (Melbourne, New York: St. Martin's Press), pp.43-63.

Walberg, J., 1981, A psychological theory of educational productivity. In Psychology and education, edited by F. H. Farley and N, Gordon (Chicago, Illinois: National Society for the Study of Education).
Wigfield, A., 1994, Expectancy-value theory of achievement motivation: A developmental perspective. Educational Psychology Review, 6, 4978.

Wu, X. G. \& Donald, J. T., 2004, Household registration system and social stratification in China: 1955-1996. Demography. 41(2), 363-384.

Wu, X. G. \& Donald, J. T., 2007, In equality and equality under Chinese socialism: The Hukou system and intergenerational occupational mobility. American Journal of Sociology,113(2), 415-445.

Wu, B. \& Zheng, Y. H., 2008, Expansion of higher education in China: Challenges and implications. Retrieved September 17 2015, from http://www.nottingham.ac.uk/cpi/documents/briefing s/briefing-36-china-higher-education-expansion.pdf

Ye, J., \& Murray, J.,2005, Left-behind children in rural China. Beijing: Social Sciences Academic press.

Yiu, L, \& Adams, J., 2013, Reforming rural education in China: understanding teacher expectations for rural youth. The China Quarterly. 216(Nov), pp.993-1017.

Young, D., Reynolds, A., \& Walberg, H., 1993, April, A hierarchical linear model of educational productivity. Paper presented at the Annual Meeting of the National Association for Research in Science Teaching. Atlanta, GA.

Zanna, M. P., \& Rempel, J. K., 1988,. Attitudes: A new book at an old concept. In Social psychology of knowledge, edited by D. Bar-Tal \& A. W. Kruglanski (Cambridge, UK: Cambridge University press), pp. 517-552.

Zeng, Z., \& Xie, Y., 2014, The effects of grandparents on children's schooling; Evidence from rural China. Demography. 51(2), 599-617.

Zhang, L., 2004, The political economy of China's equality in educational opportunities. In China education policy review 2004, edited Z. G. Yuan (Beijing: Educational Science Press).

Zhang, S., Liu, W., \& Liu, X., 2012, Investigating the relationship between protestant work ethics and Confucian dynamism: An empirical test in Mainland China. Journal of Business Ethics, 106, pp. 243-252. 